\title{
The Reform of Information Literacy Education in Colleges and Universities under the Background of Full Media
}

\author{
Yaling $\mathrm{Hu}$ \\ Literature retrieval teaching and research section of library, North Sichuan Medical College, \\ Nanchong Sichuan, 637000, China
}

Key words: Media age, College education, Information literacy, Change.

\begin{abstract}
The arrival of the media era has a certain impact on the information literacy education in colleges and universities. Under the process of carrying out information literacy education, the university can only promote the teaching and teaching function by adjusting the education and teaching work in the same way as the characteristics of the whole media Play, for the healthy growth of students to provide good support. Therefore, under the background of the new period, on the basis of fully grasping the change of information literacy education in colleges and universities in the whole media era, we should actively explore the reform of education and teaching, promote the full play of educational function and provide good support for students' healthy growth. Only in this way, the media age information literacy education can really enhance its quality, for the development of personnel training in colleges and universities to provide good support.
\end{abstract}

\section{Introduction}

The rapid development of information technology and the popular application in society have promoted the change of students' learning style and the innovation of scientific research environment. The information presentation has shown diversified development trend, and society has gradually entered the whole media era. The information literacy education of college students has a certain influence. Therefore, in the process of information literacy education, we should analyze the actual situation of information literacy education and actively explore scientific and rational teaching reform measures, hoping to improve the status quo of education, improve the quality of personnel training for the future growth of students to provide the appropriate Support and protection.

\section{The New Connotation of Information Literacy Education in the Whole Media}

In the whole media era, the basic connotation of information literacy education has changed to a certain extent, the connotation of information literacy education has new characteristics, and the information literacy education has also had some influence. Therefore, the information literacy education is studied in the new period. Analysis, should be combined with the full media era of information literacy education of the new content of a specific exploration [1]. This paper analyzes the connotation of information literacy education in the whole media era and finds out that it mainly includes traditional information literacy education, that is, it should ensure the students' information expression ability, information comprehension ability and information processing ability, etc .; visual information literacy education, Visual information, understanding and analysis of visual information, evaluation and use of visual information, in the new era of information literacy education practice has been highly valued; mobile information literacy education, that is based on mobile new media information literacy, hope with the appropriate Education and guidance to promote students in the mobile platform to obtain relevant information and the use of information ability to be significantly improved for the future development of students to lay a solid foundation. 


\section{The Change of Information Literacy Education in the Whole Media}

Under the influence of the background of the whole media era, the information literacy education in colleges and universities has undergone tremendous changes, the overall trend of change is obvious, and the personnel training has also had some influence. The actual situation of information literacy education in the whole media era is analyzed and found Mainly for the following changes.

\section{The classroom teaching model changes to the online MOOC teaching mode}

By the influence of the background of the whole media, information literacy education and teaching work in order to be able to more quickly with the Internet era of education and development environment to adapt to the times on the teaching of innovation, to provide students with more comprehensive education and guidance, Breaking the limitations of the traditional teaching work, to actively explore the $\mathrm{Mu}$ class teaching model, hoping to use the MOOC teaching platform for students to provide online and offline learning opportunities to ensure that students can combine their own actual situation reasonable choice of teaching content, highlight the teaching Value, and create conditions for the good development of student training. In this way, the traditional classroom teaching model is transformed into classroom teaching and MOOC teaching organic combination of teaching mode, can effectively promote the overall improvement of teaching quality.

In the course of learning the "literature information retrieval" course, teachers need to set up a mixed teaching mode combining online and offline teaching for the needs of the curriculum and the students' learning needs. After completing the study of classroom-related content, Can be in the MOOC education platform to obtain the relevant teaching resources, and then choose to participate in the consolidation of learning activities, expand exploration activities and in-depth study activities to ensure the rational use of teaching resources to meet the individual needs of students learning, and effectively enhance the effectiveness of education and teaching. So that the application of information technology can further highlight the value of information literacy education, information literacy education can also effectively ensure that the role of information literacy teaching in full play [2].

\section{From a single course of training to the construction of teaching and training system}

Information literacy education is generally the content of education and teaching in colleges and universities, and in the course of carrying out information literacy education is often subject to the time limit, the student information literacy ability is not ideal, the role of information literacy education play a certain adverse impact The At the same time, it analyzes the specific situation of information literacy education in colleges and universities, and finds that the curriculum training mode adopted at this stage is relatively rigid and can not guide students in the actual situation. Therefore, in the process of information literacy education change and development, from the beginning of the curriculum training mode into the teaching and training system model, can be the university education and teaching resources as a basis for the realization of the national information literacy education courses docking, to provide students with more For the rich educational resources and professional teacher guidance, and effectively ensure the information literacy education teaching effect for the future development of students to provide a solid guarantee.

\section{From the traditional teaching links gradually with the community teaching platform}

In recent years, reading has become an important part of the work of personnel training in colleges and universities. It also plays an important role in the comprehensive development of students' information literacy. For example, if college students participate in reading activities, they can generate interest in reading relevant information literacy books. Student information literacy theory of continuous strengthening, for the future development of students to provide appropriate protection [4]. Thus, the traditional information literacy teaching mode of colleges and universities gradually began to transform into classroom teaching as the main body of a variety of teaching platform combined teaching activities, teaching quality has also been further improved, the future 
development of students have a vital influences. It can be seen that the change of information literacy education in the background of the whole media can have a positive effect on the cultivation of high-quality talents. Therefore, it is necessary to strengthen the emphasis on education and teaching work and provide good support for the development of high-quality personnel training, And strive to cultivate the talent for the development of national information can contribute to the corresponding strength.

\section{New Measures for Implementing Information Literacy Education for Students in the Whole Media}

The arrival of the media age has had a crucial impact on the development of students' information literacy education. Therefore, under the current educational background, it should be adjusted according to the change of information literacy education, and the information literacy education The fit of the media era, to promote the improvement of teaching quality, talent training for the overall optimization to provide good support.

\section{Use the network teaching platform to update education and teaching model}

Real-time information literacy education for students in the full use of the network teaching platform in the process of the following two aspects should be to ensure the effectiveness of education.

First, the implementation of embedded information literacy education. It is possible to further improve the pertinence, timeliness and extensiveness of information literacy education in the process of reform and development of information literacy education, and to solve the problems in the current information literacy education practice, the lack of student learning effect, the information literacy Poor education and professional students do not match the problem, and enhance the relevance and reliability of information literacy education. In the specific operation, the information literacy education teachers in colleges and universities in order to ensure the teaching effect, we can comprehensively analyze the actual situation of information literacy education on the basis of actively explore the rational use of network teaching platform to effectively support information literacy education measures, from multiple perspectives and teachers Cooperation, and carry out a variety of embedded teaching activities, so that students in the process of receiving information literacy education is no longer limited, more professional system of learning, to achieve good educational results, information literacy education effect is bound to get Further highlights.

Second, try to introduce the flip classroom teaching mode. In the course of reform and innovation of information literacy education, combined with the influence of the whole media era, teachers can use short video to convey new knowledge to students in the course of teaching and teaching, and guide students to complete their learning tasks independently. In the classroom teaching stage, teachers need to conduct a comprehensive and systematic analysis of students' learning situation, grasp the students in the process of self-learning encountered confusion and inadequate, targeted to guide students to correct [5]. So that with the support of information literacy education, the overall quality of students can be well trained to help students develop a high-quality talent for the future development of students to provide a solid guarantee. This time in the media era of information technology and educational technology support for teaching model optimization and innovation, to further highlight the value of education and teaching work to promote the effectiveness of education and teaching for the future development of students to provide a solid guarantee.

\section{The whole media information retrieval technology should further increase the content of education and teaching}

Based on the analysis of information retrieval technology in education practice, information literacy education should focus on the following aspects: from the perspective of improving students' information literacy and media literacy,

First, the retrieval of image resources. In the information literacy education in the effective retrieval and access to relevant image information is to carry out visual material creation and rational 
use of visual materials, the basic work. In the practice of traditional information literacy education, it does not pay enough attention to the retrieval and utilization of image information resources, but it is an important part of visual literacy education in image retrieval and information literacy education. Therefore, the retrieval of image resources The important role should be fully strengthened on this teaching work of great importance,

Second, the image analysis and evaluation work. For any kind of visual material in information literacy education, it is of practical significance to carry out an objective evaluation of its contents and to understand its implied thoughts. It is also a kind of educational skill which needs to be put forward in the background of the whole media. Literacy plays a vital role. Based on this information literacy education and teaching activities, the analysis of information elements should be the main content of the image of the background, age and on-site environment and other visual factors to conduct a comprehensive analysis, to promote students to analyze problem-solving ability and critical thinking ability to gradually improve [6 ].

Third, the information visual expression aspects of the content. Information literacy education and information visualization there is a certain connection, that should use the original text information on the relevant information to accurately convey, and then use a special visualization tool to display the image, so as to achieve the main purpose of enhancing the expression of information. In the practice of visual literacy education, we can guide students to make full use of visualization tools in the process of learning and exploration. We can not only promote students' learning of knowledge, but also improve students' rational use and recognition of visual materials and promote students' Master of [7].

Fourth, the application of mobile information retrieval technology. In the context of the media age, mobile information retrieval technology in information literacy education practice has also been a relatively wide range of applications. Specifically, the mobile information retrieval technology mainly includes database technology, APP use and other technologies, the rational use of mobile new media tools for communication and communication, to achieve the mobile environment in the map of the full search and visual search, etc. Students how to get some information from the mobile device to promote the good training of students' information literacy [8].

\section{In the media era of information literacy education into the community platform teaching}

In the context of the whole media era, the implementation of the corresponding information literacy education for students can combine the changes in information literacy education in the context of the whole media era to integrate information literacy education into community platform teaching, and promote the information literacy education The development of information literacy education to enhance the flexibility to expand the scope of application of information literacy education to ensure the full play of information literacy education [9]. Specifically, combined with the different societies formed by the school, teachers in the process of leading students to participate in community education activities in the process of information literacy education can be introduced into the activities of community education, the implementation of subtle students to the impact of education, to promote the gradual formation of students Information literacy knowledge system knowledge, and gradually improve the effectiveness of teaching.

\section{Conclusions}

The arrival of the media era has a crucial impact on the information literacy education. The education and teaching staff should take full account of the actual situation in the new period in the course of implementing the information literacy education for college students, and make corresponding adjustments in the light of the actual situation. To ensure the effectiveness of education for the comprehensive development of students to provide important support. Only in this context, in the context of the media era of information literacy education can really play its important role for high-quality information personnel to create a good condition to promote the overall improvement of teaching quality. 


\section{Acknowledgement}

Fund Project:Nanchong City Social Science Research "Twelfth Five-Year Plan" 2014 general subject (NC2014B062); North Sichuan Medical College 2015 higher education teaching reform and research project (2015-12-46).

\section{References}

[1] Tang Jing, Fang Dongquan, Xiong Chan. Reflections on Information Literacy Education in Colleges and Universities Caused by imooc.com, Information Theory and Practice, 2015,38(10):42-45.

[2] Zhu Weili, Huang Qingshan, Zhou Chun.New Connotation and New Strategy of Information Literacy Education for Medical Students in the Whole Media Age,Chinese Journal of Medical Library and Information Science,2014(12):59-62.

[3] Chen Yuan.The promotion of editorial information literacy in the media publishing, Journal of Ningbo Radio \& TV University, 2014,12(3):5-8.

[4] Luo Xiujuan.Research on the All - media Education Mode of Information Literacy in University Library, Library Research, 2015,45(4):113-116.

[5] Yao Liangliang.Reflections on the Information Literacy of College Instructors in the Context of New Media, Science public (science education), 2016(8):160-161,192.

[6] Xiao Fengling. An Analysis of Medical Students' Information Literacy Education, Journal of North Sichuan Medical College, 2006, 21(06): 570-573.

[7] Xiao Fengling. New Ideas on Information Literacy Education of Medical Students from the Perspective of Metacognitive Theory, Journal of North Sichuan Medical College, 2008, 23(01): 82-86.

[8] Liu Yueling, Xiao Fengling. Investigation on Library Information Service and Information Demand and Behavior of Medical Students, Journal of North Sichuan Medical College, 2008, 23(02): 212-214.

[9] Lin Xia, Jin Bo, Xie Ying. The Application of "PBL - Case - Traditional Integrated Teaching Method" in Clinical Forensic Medicine Teaching, Journal of North Sichuan Medical College, 2010, 25(04): 390-392. 